\title{
Shear damage stress and frequency spectral characteristics of dry and saturated red sandstone determined by acoustic emission
}

\author{
Yunfei Wang ( $\nabla$ wyf_ustb@126.com ) \\ Henan Polytechnic University \\ Xiao Liu \\ Henan Polytechnic University \\ Zhen Li \\ Henan Polytechnic University
}

\section{Research}

Keywords: red sandstone, dry and saturated state, shear damage strength, acoustic emission, frequency spectrum characteristics.

Posted Date: October 9th, 2020

DOl: https://doi.org/10.21203/rs.3.rs-89153/v1

License: (9) This work is licensed under a Creative Commons Attribution 4.0 International License. Read Full License 


\title{
Shear damage stress and frequency spectral characteristics of dry and saturated red sandstone determined by acoustic emission
}

\author{
Yunfei Wang ${ }^{\mathrm{a}, 1}$, Xiao Liu ${ }^{\mathrm{b}}$, Zhen $\mathrm{Li}^{\mathrm{a}}$ \\ ${ }^{a}$ School of Civil Engineering, Henan Polytechnic University, Jiaozuo 454003, Henan, Chin \\ ${ }^{b}$ School of Energy Science and Engineering, Henan Polytechnic University, Jiaozuo 454003, Henan, China
}

\begin{abstract}
Dry and saturated red sandstone direct shear tests under different normal stresses were carried out in the rock shear test system to clarify the shear strength and damage characteristics. The cumulative ring count, cumulative energy, dominant frequency, secondary dominant frequency, and the effects of water saturation and normal stress on them were analyzed in detail. Results show that the cumulative ring count and cumulative energy curves of acoustic emission (AE) can be divided into linear increasing and step jump stages. The cumulative curves in the dry state have significant steps, thereby indicating that the repetitive process of "crack rapid development - energy accumulation" is significant. The cumulative ring count and cumulative energy are great when the normal stress is high. Under the same normal stress, the cumulative ring count and cumulative energy in the dry state are greater than those in the saturated state. The shear damage stresses were determined according to the cumulative curves. The failure process of red sandstone is divided into crack initiation and crack rapid development zones. The variation law of shear damage stress and shear strength of red sandstone is basically consistent. The growth rate of shear damage stress and strength of dry red sandstone is greater than that of saturated red sandstone with the increase in normal stress. The dominant and secondary dominant frequencies of dry and saturated red sandstone decrease with the increase in normal stress. The dominant frequency is less than the secondary frequency. Under the same normal stress, the dominant and secondary dominant frequencies of red sandstone shear failure in the dry state are less than those in the saturated state, thereby indicating that the shear microcrack scale of red sandstone in the saturated state is smaller than that in the dry state. The results have a certain theoretical significance to determine the shear damage degree of red sandstone by AE monitoring.
\end{abstract}

Keywords: red sandstone, dry and saturated state, shear damage strength, acoustic emission, frequency spectrum characteristics.

\section{Introduction}

The rapid release of strain energy will cause acoustic emission (AE) during rock deformation and failure. The AE signal contains the characteristic information of rock damage and crack development. This approach is an effective way to study the process of rock damage and fracture to obtain the key information of rock damage and fracture by analyzing the AE signal. The damage degree of rock mass engineering during deformation and failure can be analyzed through $\mathrm{AE}$ monitoring. The microcrack evolution mechanism of rock engineering and the precursor information of rock failure can be further explored.

The AE technology is increasingly widely used in engineering. In the aspect of AE of rock deformation and failure, many scholars have carried out relevant research from different aspects. Ghasemi et al. [1] investigated the microcrack features and type and identified the damage stress threshold by AE measurements. Bruning et al. [2] presented the identification of crack stress thresholds and damage evolution of brittle granite. Saadat et al. [3] assessed the effect of joint roughness coefficient on

${ }^{1}$ Corresponding author at: School of Civil Engineering, Henan Polytechnic University, 2001 Century Road, High Tech District, Jiaozuo 454000, Henan, China E-mail address: wyf_ustb@126.com (Yunfei Wang) asperity damage and shear mechanism of rock joints under constant normal load and constant normal stiffness conditions. Zhao et al. [4] derived the general compression shear failure criterion of the equivalent model, which considers the cohesive strength of the interface coal and soft rock. Bost et al. [5] compared the shear strength in different scales and proposed an analytical model that evaluates the shear strength in the metric scale. Moradian et al. [6] analyzed the count and energy parameters of the AE signals during direct shear test on different types of joints to monitor the shear behavior of the joints. Wang et al. [7] revealed that the accumulative AE count/energy of granite decreases with the increase in the number of freeze-thaw cycles, and the samples is prone to producing large-scale cracks under high freeze-thaw treatment. Shi et al. [8] studied the 3D evolution law of microcracks in the fine sandstone specimens with two pre-existing cracks on the basis of the spatial evolution of AE events. Rodríguez et al. [9] applied AE monitoring for the qualitative and quantitative assessment of the fracturing process in rocks and pointed out that crack propagation is characterized by wide-band emissions regardless of the rock type. Aker et al. [10] studied AEs associated with shear and tensile failures in the sandstone sample to relate the $\mathrm{AE}$ event rate to the macroscopic deformation of the sample. Mao et al. [11] studied the behavior of crack deflection of large-scale granite specimens in the hydraulic fracturing 
process by recording the AE events. Wang et al. [12] evaluated the shear failure and $\mathrm{AE}$ counts of jointed rock-like specimens under compressive shear loading. Mpalaskas et al. [13] indicated that AE can characterize the difference between the fractural modes by using simple feature analysis on the bending and shear experiments of granite. Zhang et al. [14] evaluated the $\mathrm{AE}$ characteristics of nonpersistent joints by the hit rate, energy rate, and $b$ value and revealed that $a$ low $b$ value indicates an intense shear failure. Shkuratnik et al. [15] obtained changes in shear strains and AE activity of rock salt as functions of time and temperature under different axial stresses. Li et al. [16] proposed that the distribution of AE energy of the intact and single fissured specimens followed a power law distribution. Moradian et al. [17] reported that the coalescence of the microcracks produces macrocracks. The macrocrack can be efficiently detected by a sharp increase in the $\mathrm{AE}$ parameters. Srinivasan et al. [18] investigated the effect of thermal treatment on the mechanical and fracturing behavior of shale and used AE signals to identify the changes brought in by temperature variations on the crack damage zones in shale. Barile et al. [19] summarized the AE parameters, their advantages, limitations, and applications in the damage evolution and discussed the clustering of AE data and its advantages in effective damage characterization. Zhang et al. [20] used a short time Fourier transform to analyze the $\mathrm{AE}$ signals to obtain the frequency and classified the signals by fuzzy C-means method. Liu et al. [21] proposed a frequency division processing method for the standard description expressions of discrete signals and investigated the frequency evolution of rock under uniaxial loading conditions.

The previous research reported that researchers have made many beneficial achievements in shear strength and AE characteristics of rock joints, which mainly studied the change law of AE parameters with different joint surface morphologies and normal stresses. However, studies on shear damage stress and frequency spectrum of AE of dry and saturated red sandstone are limited and need to be further improved. The direct shear tests of dry and saturated red sandstone were carried out to study the influence of normal stress and saturated water on the frequency spectrum and shear damage stress.

\section{Samples and test method}

\subsection{Sample preparation}

According to the international rock mechanical sample processing standard, red sandstone was processed into cylindrical samples with a diameter and height of 50 and $100 \mathrm{~mm}$, respectively. The red sandstone samples were selected on the basis of their P-wave velocity and appearance to ensure homogeneity of samples and reliability of the test data. Samples with obvious defects and large difference in P-wave velocity were removed. The average longitudinal wave velocity and average density of dry red sandstone are $2.948 \mathrm{~km} / \mathrm{s}$ and 2401 $\mathrm{kg} / \mathrm{m}^{3}$, respectively. The average density of saturated red sandstone is $2472 \mathrm{~kg} / \mathrm{m}^{3}$, and the saturated water absorption is $2.96 \%$. Dry and saturated red sandstone samples are shown in Fig. 1.

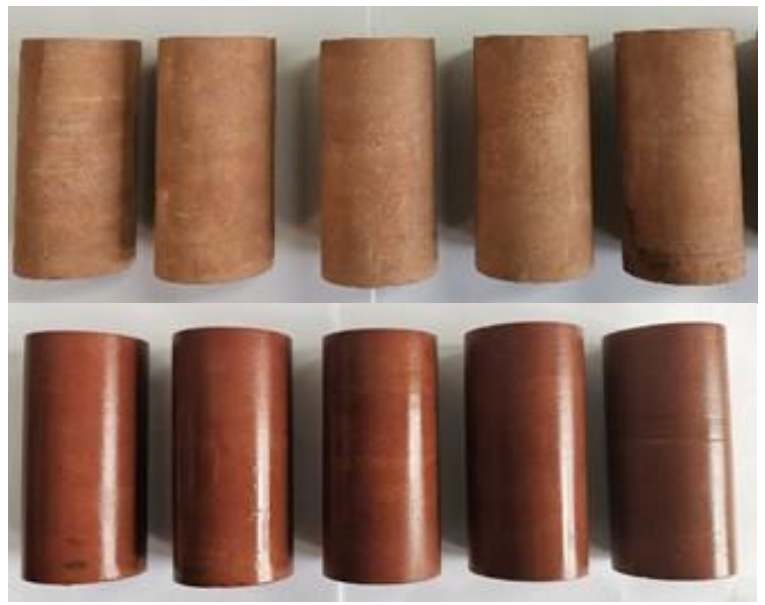

Fig. 1 Dry and saturated samples of red sandstone

\subsection{Device and method}

The rock direct shear device (JiNan Rock Test Device Co., Ltd., China) composed of a normal oil cylinder, tangential oil cylinder, shear box, control system, and acquisition system can complete the shear strength test of intact rock and joint by adopting the fully automatic closed-up control of force and displacement (Fig. 2). The maximum normal load, maximum normal displacement, and measurement accuracy of the normal displacement sensor are $1000 \mathrm{kN}, 300 \mathrm{~mm}$, and 0.001 $\mathrm{mm}$, respectively. The maximum horizontal load, maximum horizontal displacement, and measurement accuracy of horizontal displacement sensor are $600 \mathrm{kN}$, $100 \mathrm{~mm}$, and $0.001 \mathrm{~mm}$, respectively.

The full information $\mathrm{AE}$ monitoring system was adopted in the direct shear tests. The sampling frequency was $3 \mathrm{MHz}$. Four AE monitoring probes were uniformly arranged at the bottom of the sample (Fig. 3). AE monitoring and direct shear test were simultaneously carried out.

In the dry and saturated shear test, the normal loading rate is $0.5 \mathrm{kN} / \mathrm{s}$, and the normal stress is loaded to $5,10,20,30$, and $40 \mathrm{MPa}$ to achieve constant normal stress. Red sandstone is sheared at the rate of $0.005 \mathrm{~mm} / \mathrm{s}$ until the samples failed. A dry or saturated sample is tested under each normal stress. The test will be supplemented if it fails.

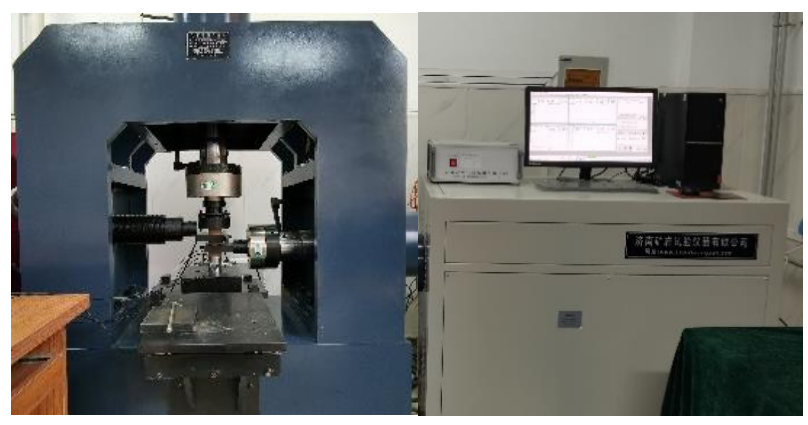

Fig. 2 Direct shear test device 


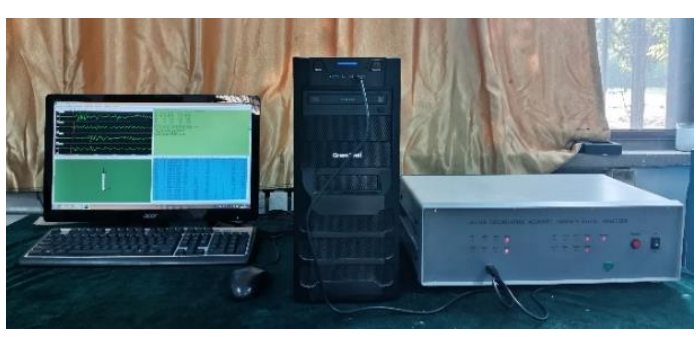

(a) Monitoring system of $\mathrm{AE}$

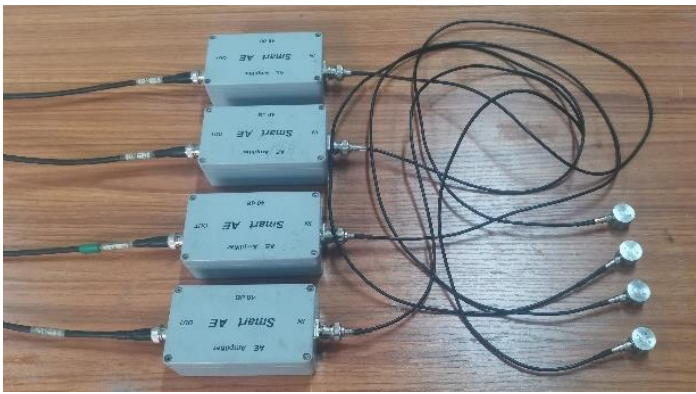

(b) Amplifiers and monitoring probes

Fig. 3 AE monitoring system

The test procedure is presented as follows:

1) Red sandstone samples selected on the basis of appearance and P-wave velocity were divided into two batches of direct shears under dry and saturated states.

2) Preparation of dry and saturated samples: The samples were placed in an oven to dry at $105{ }^{\circ} \mathrm{C}$ for $24 \mathrm{~h}$ (dry samples). The samples were saturated in

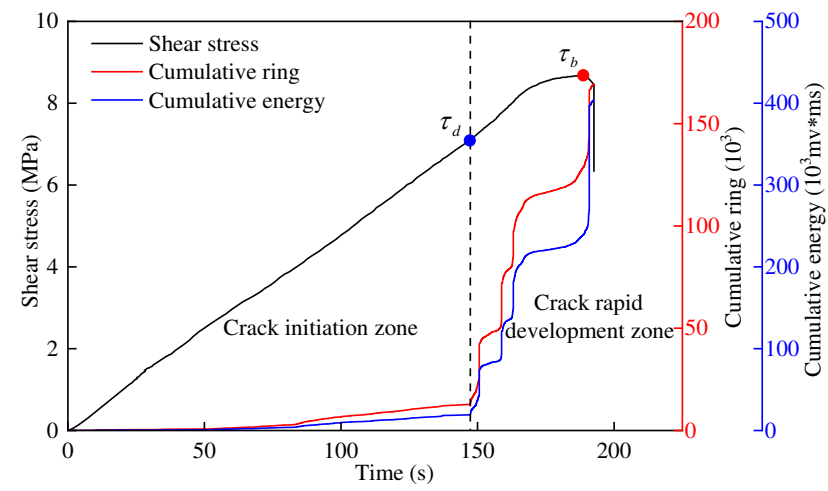

(ad5) Dry state (5 MPa)

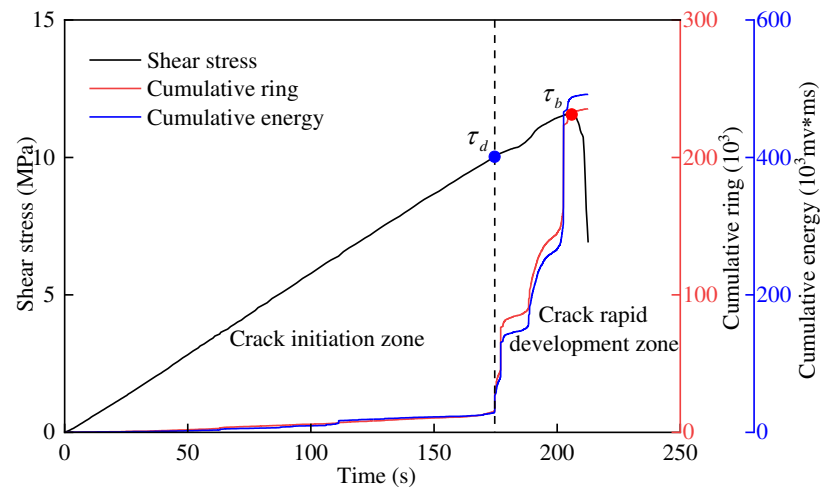

$\left(b_{d 10}\right)$ Dry state (10 MPa) water and then weighted once every other day until the weight becomes constant (saturated samples).

3) Normal loading: The normal stresses $(5,10,20$, 30 , and $40 \mathrm{MPa}$ ) were applied to the predetermined stress level at the rate of $0.5 \mathrm{kN} / \mathrm{s}$ to achieve constant normal stress.

4) Tangential loading: The normal stress was maintained for each direct shear test, and the tangential force was applied at the rate of $0.005 \mathrm{~mm} / \mathrm{s}$ until the sample failed.

5) $\mathrm{AE}$ monitoring: The $\mathrm{AE}$ signal was simultaneously monitored when the direct shear test of red sandstone was carried out.

6) Result analysis: Shear damage stress, shear strength, and $\mathrm{AE}$ frequency spectral characteristics of dry and saturated red sandstone were analyzed.

\section{Analysis of test results}

\subsection{Shear damage analysis by $\mathrm{AE}$}

The variation of shear stress, cumulative ring count, and cumulative energy of dry and saturated red sandstone under different normal stresses with time is illustrated in Fig. 4. The subscripts $\mathrm{d} 5$ and $\mathrm{s} 5$ of $\mathrm{a}_{\mathrm{d} 5}$ and $\mathrm{a}_{\mathrm{s} 5}$ in Fig. 4 represent the corresponding curves of $5 \mathrm{MPa}$ normal stress in the dry state and $5 \mathrm{MPa}$ normal stress in the saturated state, respectively. The other subscripts are the same.

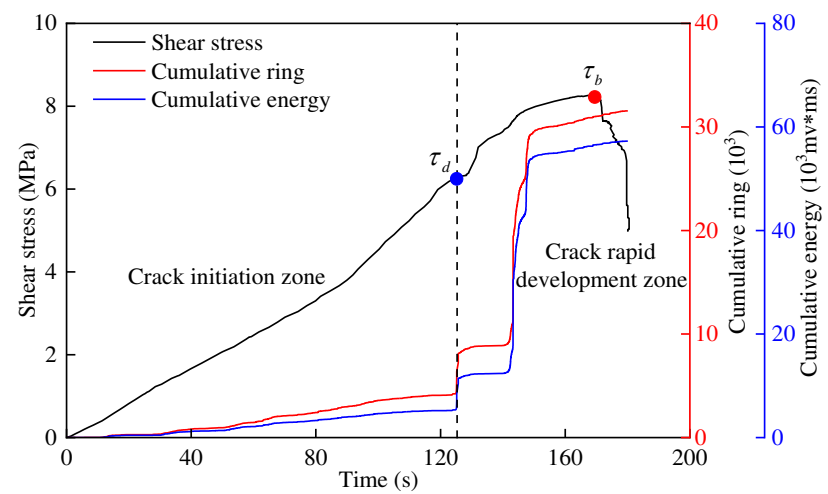

(as5) Saturation state (5 MPa)

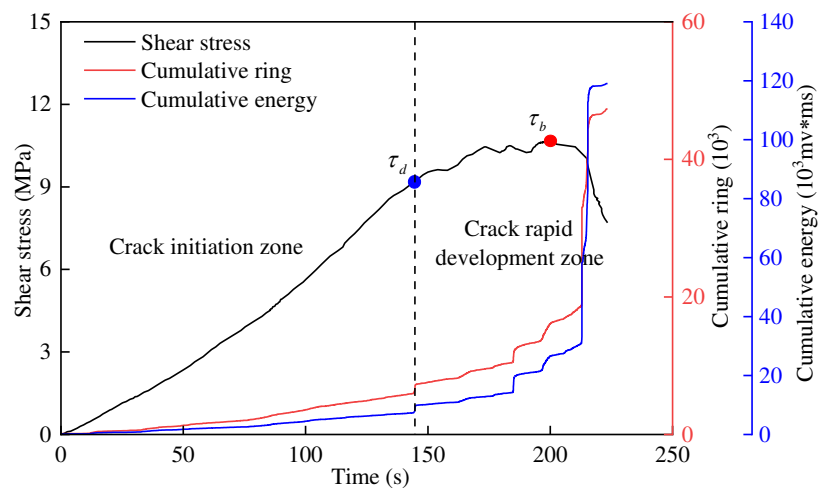

$\left(b_{s 10}\right)$ Saturation state $(10 \mathrm{MPa})$ 


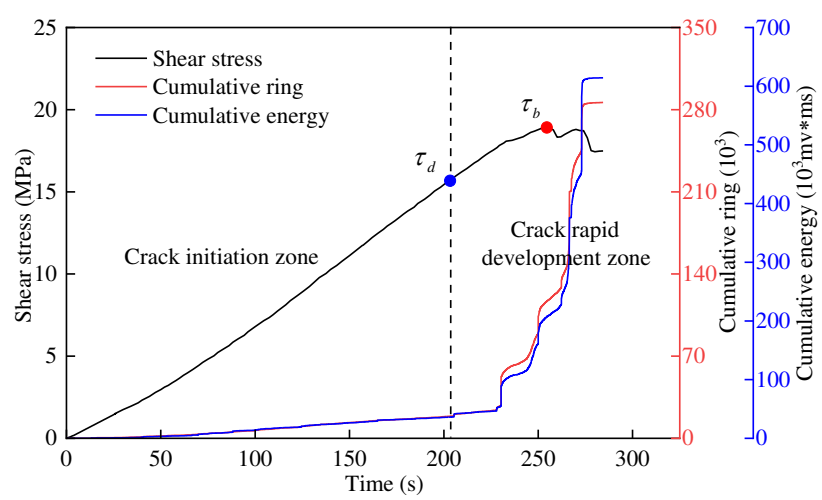

$\left(\mathrm{c}_{\mathrm{d} 20}\right)$ Dry state (20 MPa)

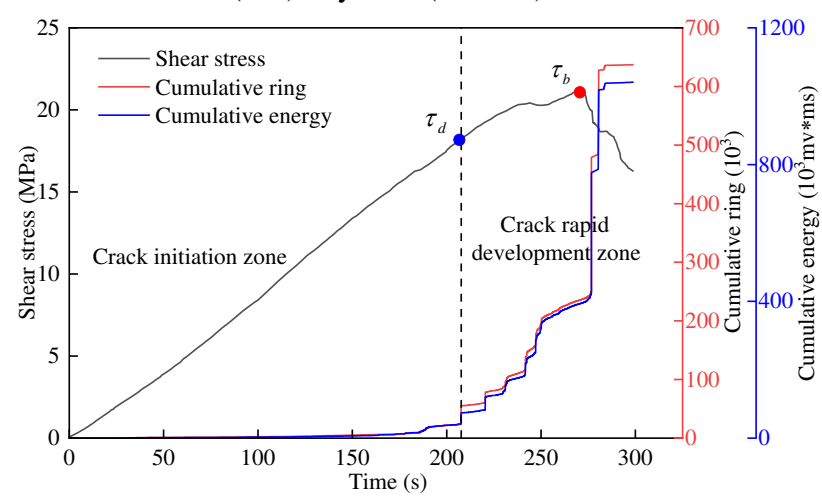

$\left(\mathrm{d}_{\mathrm{d} 30}\right)$ Dry state $(30 \mathrm{MPa})$

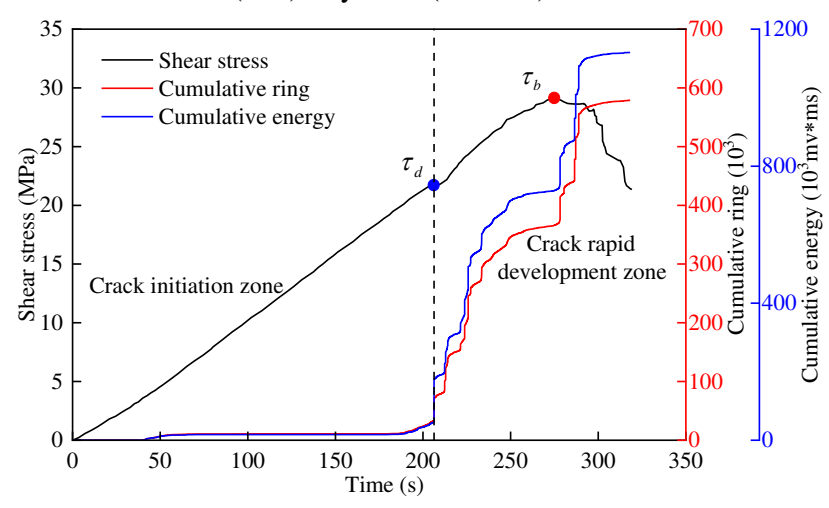

(ed40) Dry state (40 MPa)

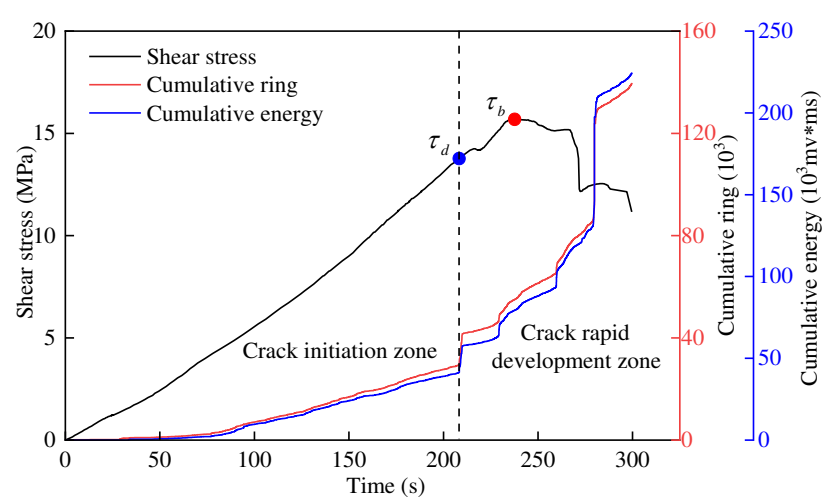

$\left(\mathrm{c}_{\mathrm{s} 20}\right)$ Saturation state $(20 \mathrm{MPa})$

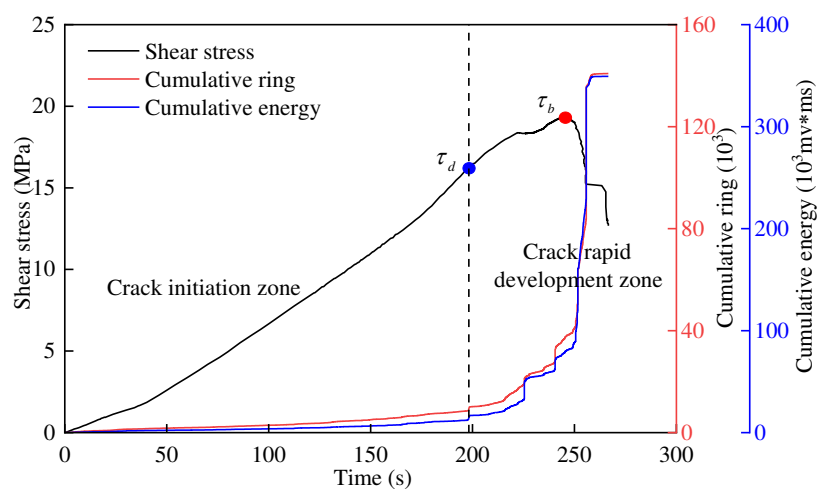

$\left(\mathrm{d}_{\mathrm{s} 30}\right)$ Saturation state $(30 \mathrm{MPa})$

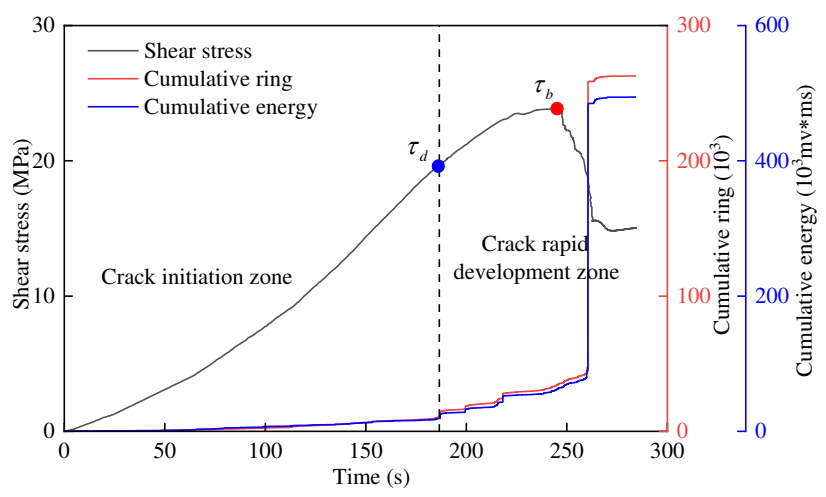

$\left(\mathrm{e}_{s 40}\right)$ Saturation state $(40 \mathrm{MPa})$

Fig. 4 AE cumulative ring count and energy curves of the dry and saturated red sandstone

In the shear process of red sandstone, microcracks will appear, develop, and coalesce in the shear plane with the increase in shear displacement. The transient elastic wave will be generated along with the release of energy. The shear damage evolution mechanism can be analyzed by $\mathrm{AE}$ monitoring. In this study, the cumulative ring count and cumulative energy curves are used to analyze the shear damage evolution characteristics of dry and saturated red sandstone.

Fig. 4 shows that the variation of the cumulative ring count and cumulative energy curves of AE of dry and saturated red sandstone under different normal stresses with time is similar. Accordingly, the cumulative ring count curves are selected for the analysis of shear damage evolution. The cumulative ring count curve is overall stepped, which can be divided into two stages: linear increasing and step jump stages. In the linear increasing stage, the shear microcracks randomly form, and microcracks gradually develop. However, the number is limited. In the step jump stage, microcracks rapidly develop and coalesce with each other, which belongs to the unstable development stage of damage. The cumulative ring count and cumulative energy of red sandstone in shear failure are increased with the increase in normal stress. Under the same normal stress, the cumulative ring count and energy of red sandstone in dry state are greater than those in the saturated state.

According to the change law of cumulative ring count and cumulative energy curves, the shear failure process of red sandstone is divided into two zones: crack initiation and crack rapid development zones. 
The shear stress corresponding to the dividing point of the two zones is called shear damage stress $\left(\tau_{d}\right)$. The crack initiation zone corresponds to the linear increasing stage of $\mathrm{AE}$ cumulative ring count curve. The crack rapid development zone corresponds to the step jump stage of the AE cumulative ring count curve. The crack initiation zone is the random formation stage of microcracks. The crack rapid development zone is mainly the further development and coalesce stage of cracks, which represents the rapid and unstable development stage of rock internal damage.

The cumulative ring count curves of dry red sandstone have many significant steps compared with those of saturated red sandstone, thereby indicating that the damage and fractural process of dry red sandstone is more obvious. Specifically, the repeated process from crack rapid development to energy accumulation is remarkable. The shear failure of saturated red sandstone in the later stage of unstable development of cracks is mainly caused by the sudden of multiple cracks. Meanwhile, the shear failure of dry red sandstone is a progressive process. The step property of damage development of dry red sandstone becomes obvious with the increase in normal stress. The sudden coalesce characteristics of saturated red sandstone also become significant.

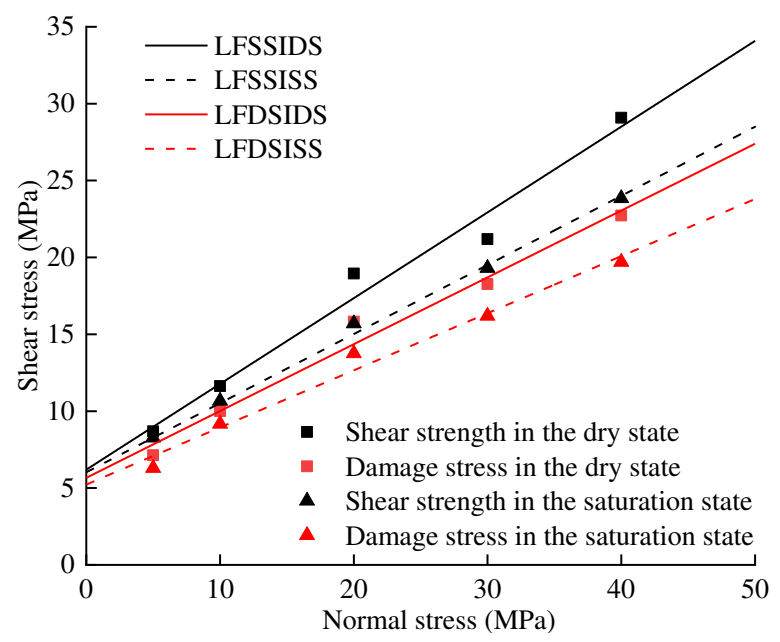

Fig. 5 Shear strength and damage stress of red sandstone under different normal stresses

In Fig. 5, LFSSIDS, LFSSISS, LFDSIDS, and LFDSISS denote the linear fitting of shear strength of red sandstone in the dry state, the linear fitting of shear strength in the saturated state, the linear fitting of damage stress in the dry state, and the linear fitting of damage stress in the saturated state, respectively.

According to the normal or shear load of dry or saturated red sandstone at failure, the normal and shear stress acting on the shear plane are calculated according to Formulas (1) and (2), respectively.

$$
\begin{gathered}
\sigma_{n}=F_{n} / A, \\
\tau=F_{s} / A,
\end{gathered}
$$

where $\sigma_{n}$ is the normal stress acting on the shear plane; $\tau$ is the shear stress, and the maximum value is the shear strength $\tau_{b} ; F_{n}$ is the normal load; $F_{s}$ is the shear load; and $A$ is the area of the shear plane.

The shear strength $\tau_{b}$ and damage stress $\tau_{d}$ of the dry and saturated red sandstone under different normal stresses are plotted in Fig. 5. The Coulomb expressions of shear strength and damage stress of red sandstone are obtained via linear fitting under dry and saturated states as follows:

The shear strength Coulomb expressions of dry and saturated red sandstone are as follows:

$$
\begin{aligned}
& \tau_{b}=6.20+0.5578 \sigma_{n}, \\
& \tau_{b}=6.02+0.4495 \sigma_{n} .
\end{aligned}
$$

The shear damage stress Coulomb expressions of dry and saturated red sandstone are as follows:

$$
\begin{aligned}
& \tau_{d}=5.66+0.4346 \sigma_{n}, \\
& \tau_{d}=5.23+0.3715 \sigma_{n} .
\end{aligned}
$$

Formulas (3) and (4) are the expressions of shear strength of the dry and saturated red sandstone, respectively. Formulas (5) and (6) are the expressions of shear damage stress of the dry and saturated red sandstone, respectively.

Fig. 5 illustrates that the shear strength and damage stress of dry and saturated red sandstone linearly increase with the increase in normal stress. The change law is basically the same. The difference of shear strength or shear damage stress of the red sandstone between dry and saturated states is great when the normal stress is large. The increase rate of shear strength and damage stress of red sandstone in the dry state is greater than that in the saturated state with the increase in normal stress. In the dry and saturated states, the cohesion rates determined by damage stress are $91.29 \%$ and $86.88 \%$ of those determined by shear strength, respectively.

\subsection{Damage degree function}

This section analyzes the change rule between damage degree and shear strain during the shear failure of dry and saturated red sandstone.

First, the calculation of shear strain in the direct shear test is provided. The shear displacement of red sandstone is small during shear failure, according to Fig. 8. Hence, the shear strain $\gamma$ of the shear zone can be expressed as follows:

$$
\gamma=\frac{s d}{h},
$$

where $\gamma$ is shear strain, $s d$ is the shear displacement, and $h$ is the height of the shear zone, which is set to 15 $\mathrm{mm}$ in tests. 


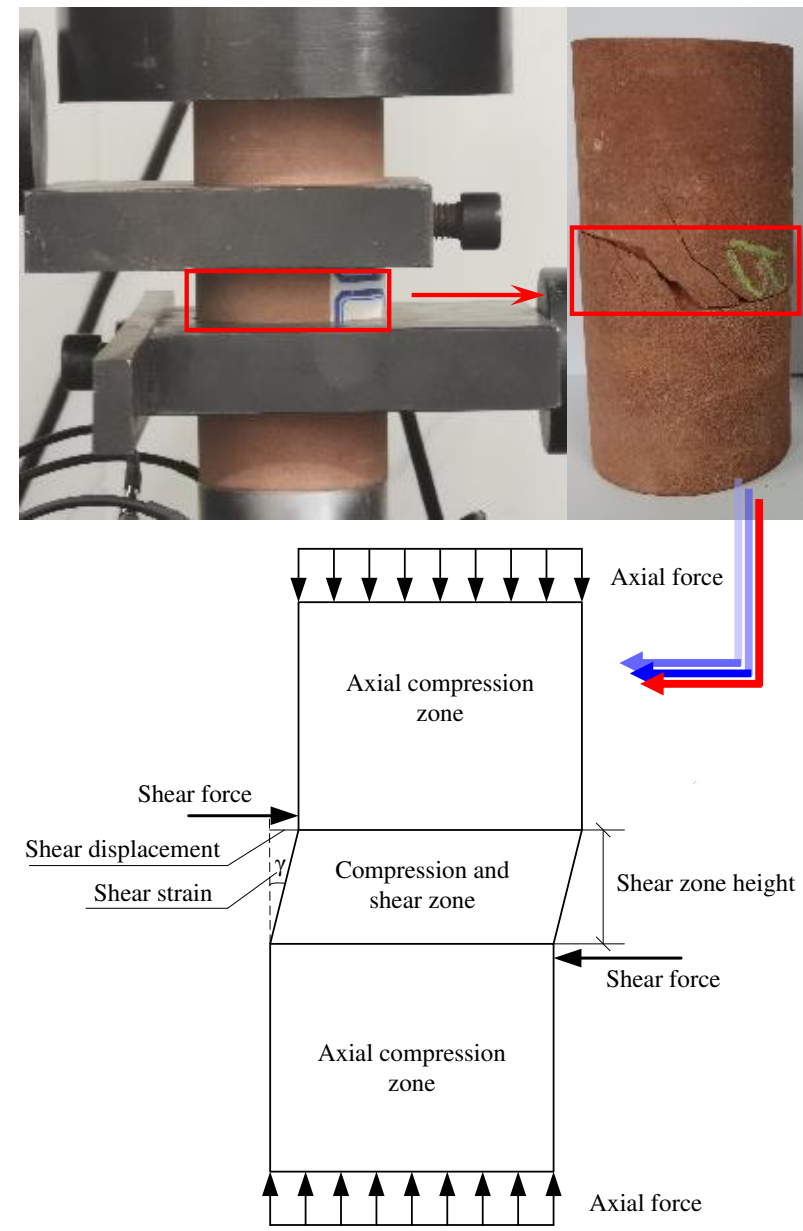

Fig. 6 Diagram of the shear strain calculation

Second, the calculation of damage degree of red sandstone is provided. Kachanov [22] defined damage degree (D) as:

$$
D=\frac{A_{d}}{A},
$$

where $A_{d}$ is the projected area of the damage on the shear plane, and $A$ is the area of the shear plane.

Each $\mathrm{AE}$ ring corresponds to a microdamage in rock. The maximum cumulative ring count corresponds to the complete fracture of the shear plane. Therefore, the AE ring count corresponding to the unit area fracture of shear plane is as follows:

$$
R_{u a}=\frac{R_{\max }}{A},
$$

where $R_{\text {и }}$ is the cumulative ring count corresponding to unit area fracture of shear plane, and $R_{\max }$ is the maximum cumulative ring count.

When the cumulative damage area is $A_{d}$, the corresponding to cumulative ring count $R_{d}$ is as follows:

$$
R_{d}=\frac{R_{\max }}{A} \mathrm{~A}_{d} .
$$

The damage degree $D$ of shear failure of red sandstone expressed by the cumulative ring count is obtained:

$$
D=\frac{A_{d}}{A}=\frac{R_{d}}{R_{\max }} .
$$

Formula (11) is used to calculate the damage degree of the dry and saturated red sandstone under different normal stresses. The change rule of the damage degree with shear strain is plotted in Fig. 7.

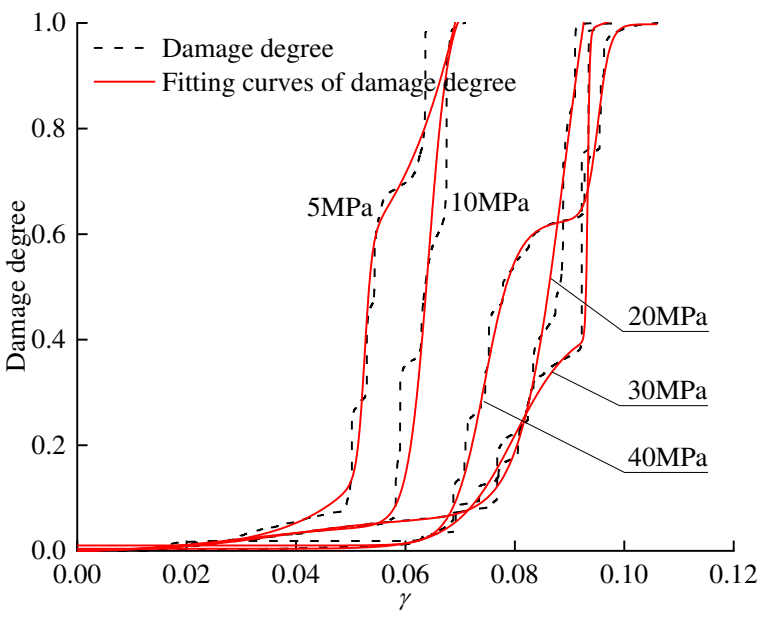

(a) Dry state

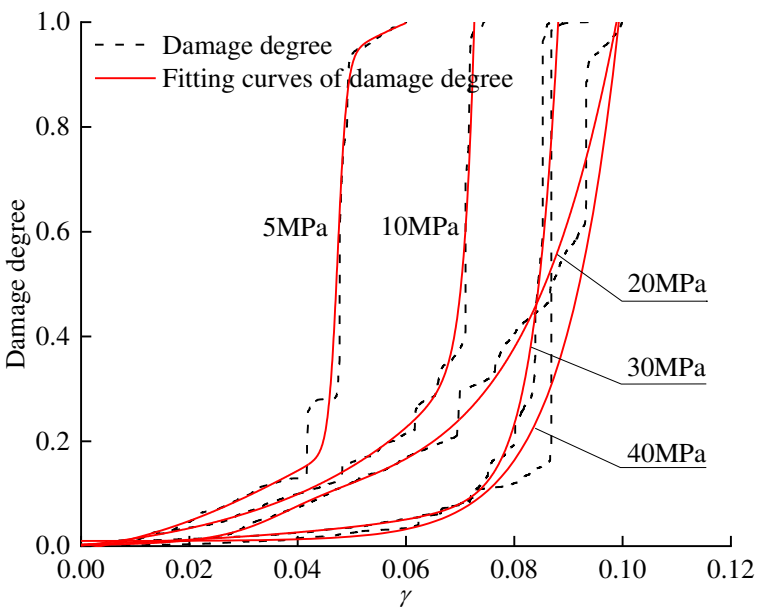

(b) Saturated state

Fig. 7 Variation of the damage degree of red sandstone with shear strain in the dry and saturated states

Fig. 7 shows that the relationship between damage degree and shear strain of dry and saturated red sandstone can be expressed as a double dose response function.

$$
D=A 1+(A 2-A 1)\left[\frac{p}{1+10^{(B 1-\gamma) h 1}}+\frac{1-p}{1+10^{(B 2-\gamma) h 2}}\right],
$$

where $D$ is the damage degree; and $A 1, A 2, B 1, B 2, h 1$, $h 2$, and $p$ are the fitting coefficients.

The damage degree value is taken as 1 when the calculation value of damage degree function (12) is greater than 1 to conform to the reality. The fitting coefficients of damage degree function for dry and saturated red sandstone under different normal stresses are listed in Table. 1. D5 and S5 in Table 1 indicate the 
damage degree of dry red sandstone under $5 \mathrm{MPa}$ normal stress and the damage degree of saturated red sandstone under $5 \mathrm{MPa}$ normal stress, respectively. The symbols are the same.

Table 1. Fitting coefficients of the damage degree function

\begin{tabular}{cccccccc}
\hline Case & $A 1$ & A2 & $B 1$ & $B 2$ & $h 1$ & $h 2$ & $p$ \\
\hline D5 & -0.0018 & 24.4005 & 0.0525 & 0.1155 & 634.82 & 34.96 & 0.0182 \\
D10 & -0.0048 & 1.0572 & 0.0312 & 0.0642 & 35.65 & 231.28 & 0.0540 \\
D20 & -0.0022 & 1.3983 & 0.0383 & 0.0891 & 38.26 & 107.56 & 0.0476 \\
D30 & 0.00382 & 1.0191 & 0.0800 & 0.0933 & 80.59 & 2241.02 & 0.4235 \\
D40 & 0.0102 & 0.9976 & 0.0745 & 0.0952 & 151.32 & 394.12 & 0.6245 \\
- S5 & -0.0438 & 1.1155 & 0.0430 & 0.0474 & 23.32 & 511.98 & 0.3523 \\
S10 & -0.0335 & 47.1552 & 0.0921 & 0.0792 & 14.68 & 239.98 & 0.4843 \\
S20 & -9.4708 & 103.9545 & 0.0367 & 0.1783 & 78.31 & 25.78 & 7.3247 \\
S30 & -0.0110 & 77.4878 & 0.2732 & 0.1074 & 10.43 & 97.30 & 0.1306 \\
S40 & 0.0098 & 286.8406 & 0.2097 & 0.2196 & 41.85 & 123.40 & 143.40 \\
\hline
\end{tabular}

Fig. 7 shows that the damage degree of red sandstone gradually increases with the increase in shear strain. The damage degree slowly increases when the shear strain is less than the shear strain corresponding to the damage stress. The damage degree rapidly increases when the shear strain is greater than the shear strain corresponding to the damage stress, thereby indicating that the damage degree of red sandstone becomes rapid and unstable

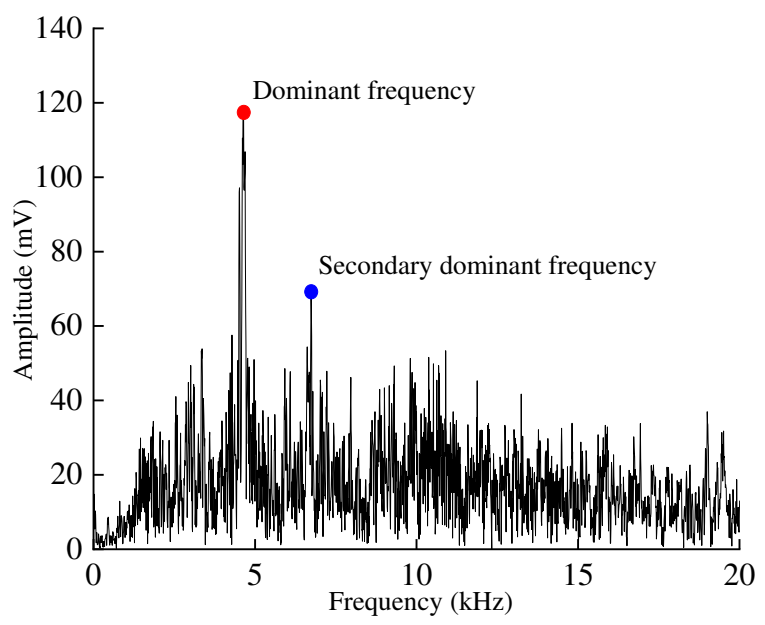

(ad5) Dry state (5 MPa) when the shear strain reaches a certain value.

\subsection{Frequency spectral characteristics of $\mathrm{AE}$}

The key information of the AE signal can be mined via the spectral analysis of the AE signal. The frequency spectral characteristics extracted from signal analysis can fully reflect the shear damage feature, which is of great significance to reveal the damage evolution mechanism of red sandstone shear failure and capture the precursor of rock shear failure.

The AE signal is a type of unstable signal, and its frequency spectral characteristics can be analyzed by fast Fourier transform. First, the AE wave with strong signal is selected from different channels. Second, the typical band from shear damage to shear failure is selected in the signal wave. Finally, the extracted bands are analyzed by MATLAB program to obtain the frequency spectral characteristics, and the frequency spectral diagrams are plotted. In the frequency spectral diagram, the frequency corresponding to the maximum amplitude is defined as the dominant frequency. The frequency corresponding to the second largest amplitude is defined as the secondary dominant frequency. The energy of the AE signal is mainly concentrated in these two frequency bands. The above analysis indicated that the dominant and secondary frequencies of the typical AE signal band released during shear failure of the dry and saturated red sandstone under different normal stresses are obtained (Fig. 8).

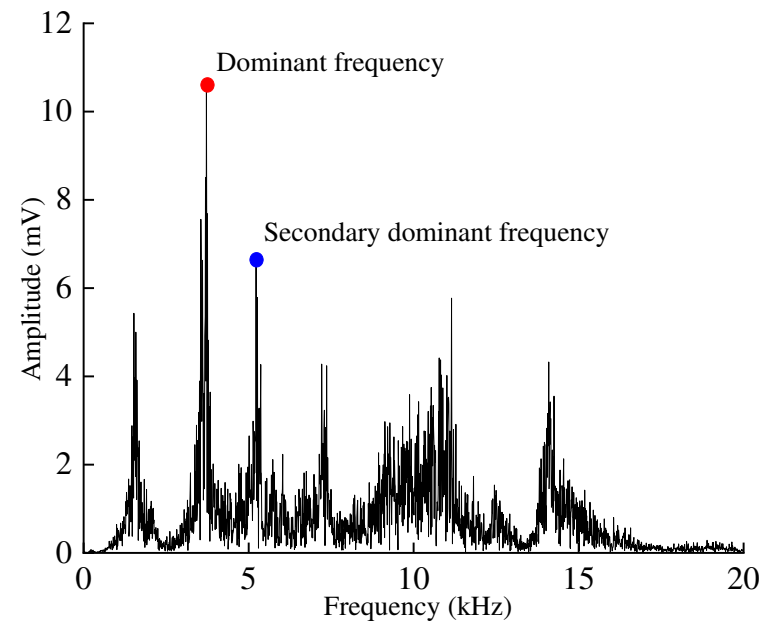

(ass) Saturation state (5 MPa) 


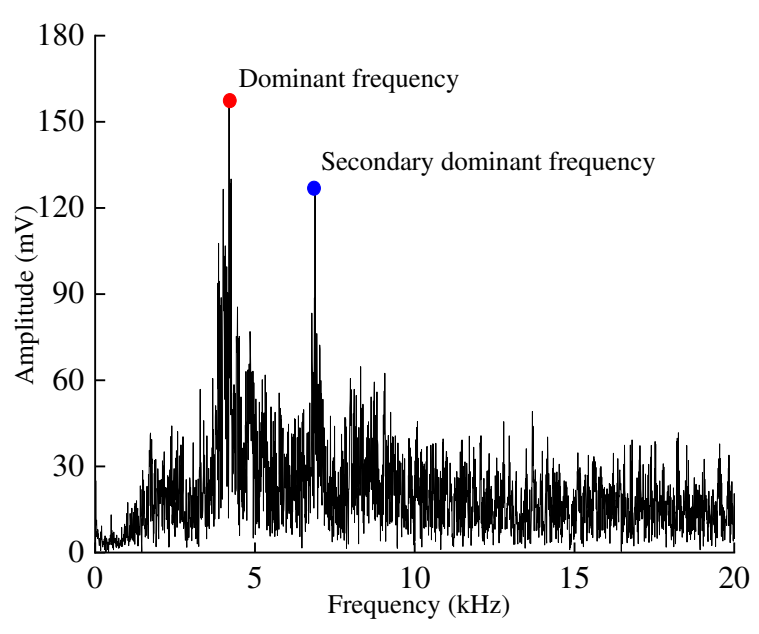

$\left(b_{d 10}\right)$ Dry state (10 MPa)

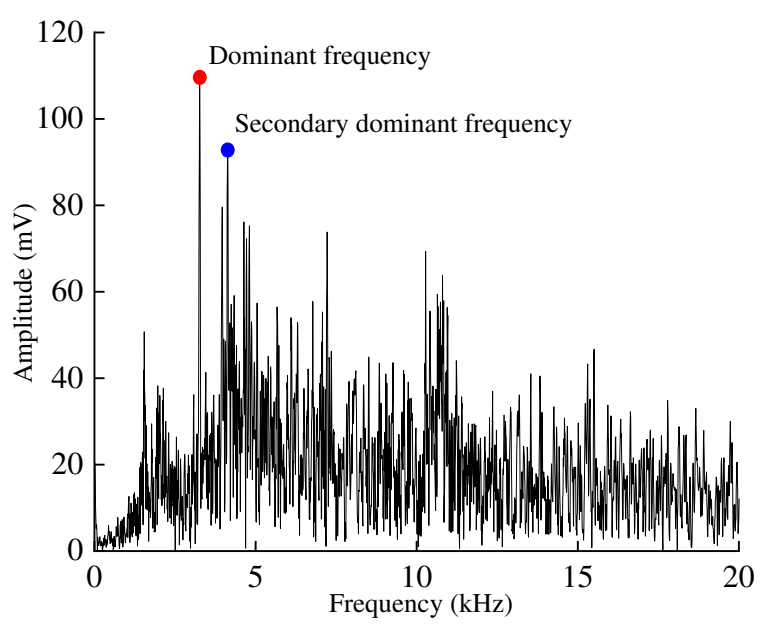

$\left(\mathrm{c}_{\mathrm{d} 20}\right)$ Dry state $(20 \mathrm{MPa})$

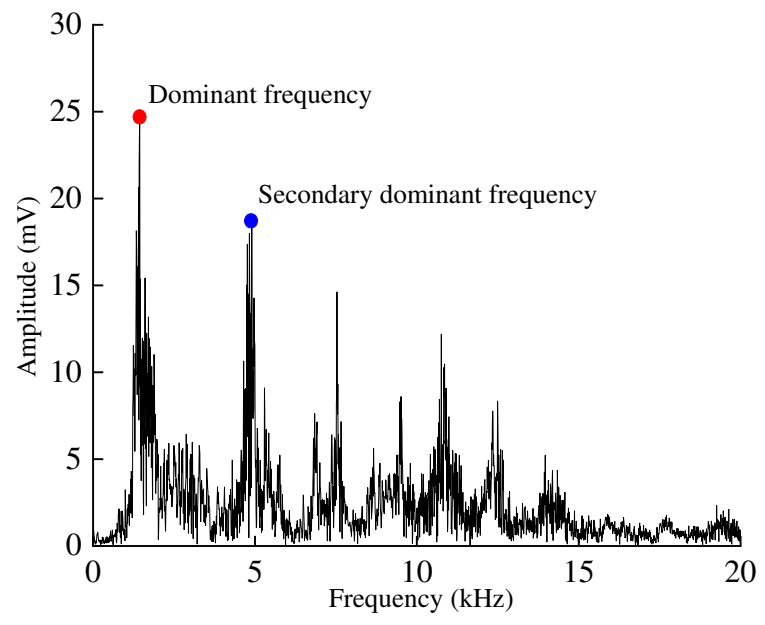

$\left(\mathrm{d}_{\mathrm{d} 30}\right)$ Dry state $(30 \mathrm{MPa})$

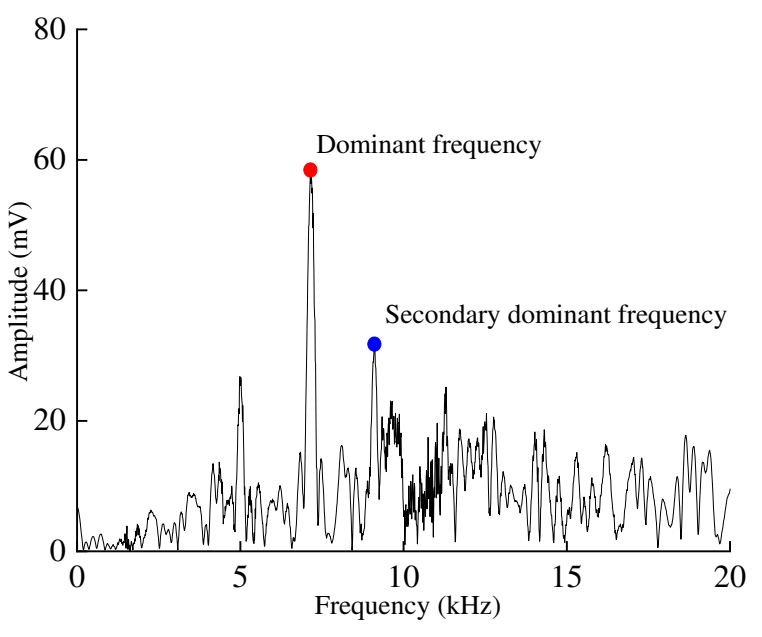

$\left(\mathrm{b}_{\mathrm{s} 10}\right)$ Saturation state (10 MPa)

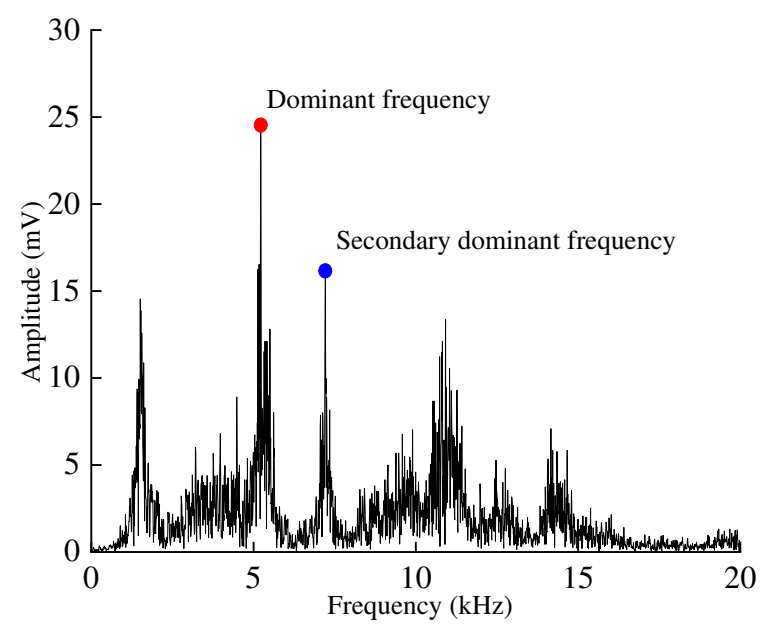

( $\left.\mathrm{c}_{\mathrm{s} 20}\right)$ Saturation state $(20 \mathrm{MPa})$

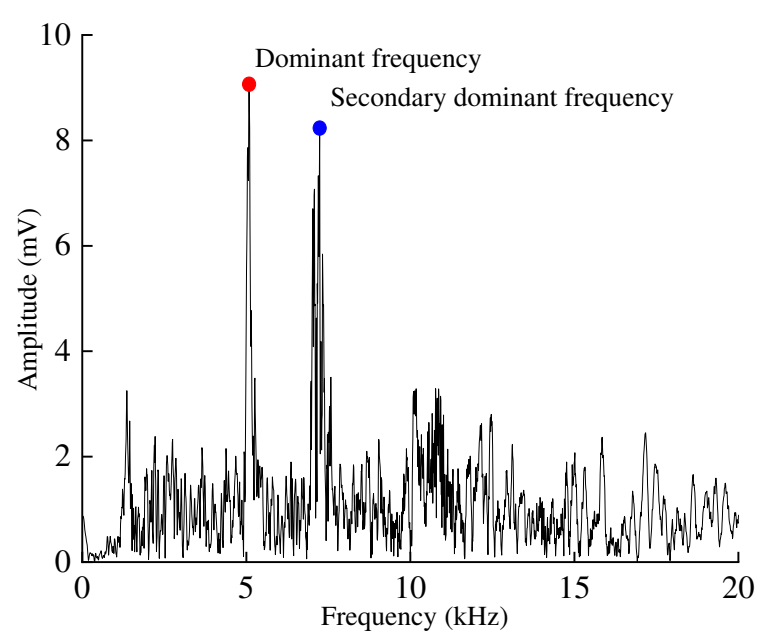

$\left(\mathrm{d}_{\mathrm{s} 30}\right)$ Saturation state $(30 \mathrm{MPa})$ 


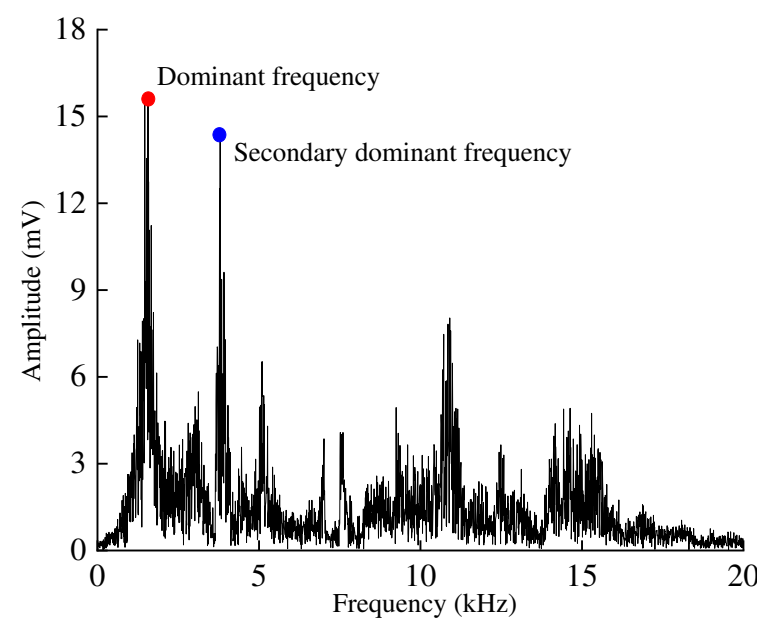

(ed40) Dry state (40 MPa)

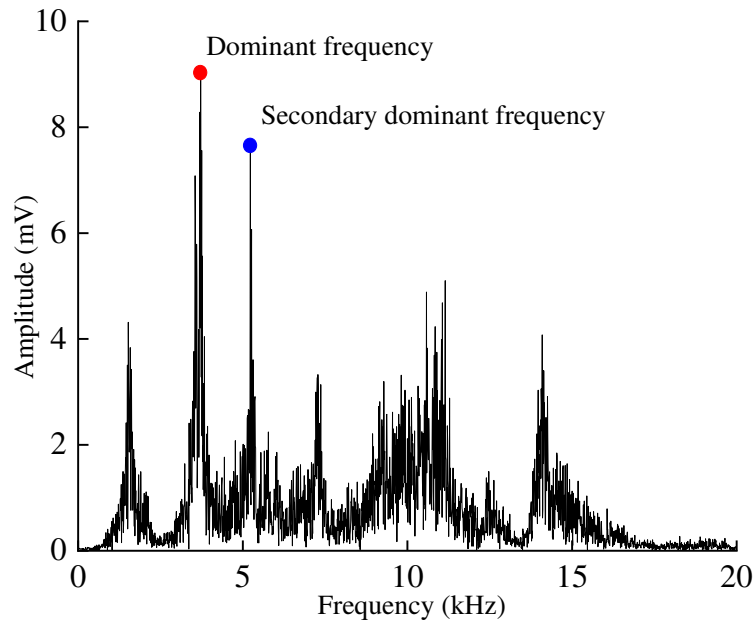

$\left(\mathrm{e}_{\mathrm{s} 40}\right)$ Saturation state $(40 \mathrm{MPa})$

Fig. 8 Frequency spectral characteristics of AE of the dry and saturated red sandstone

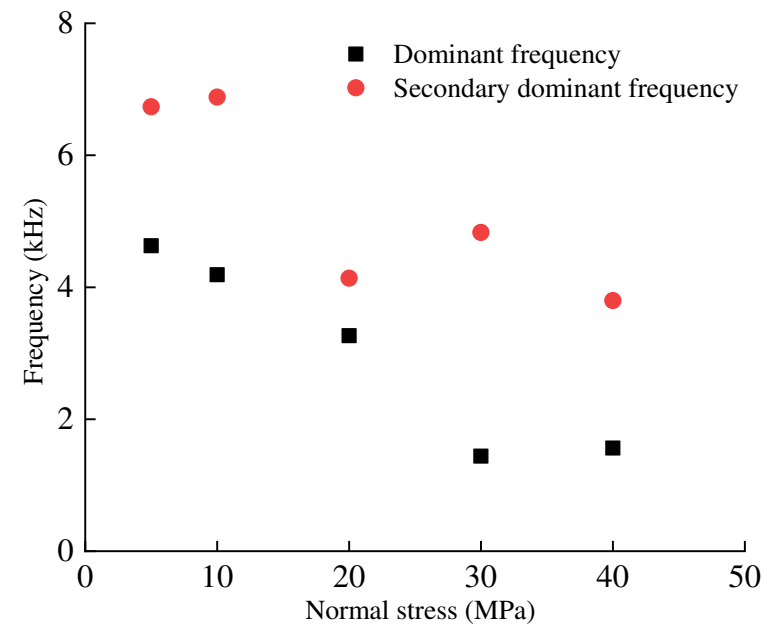

(a) Dry state

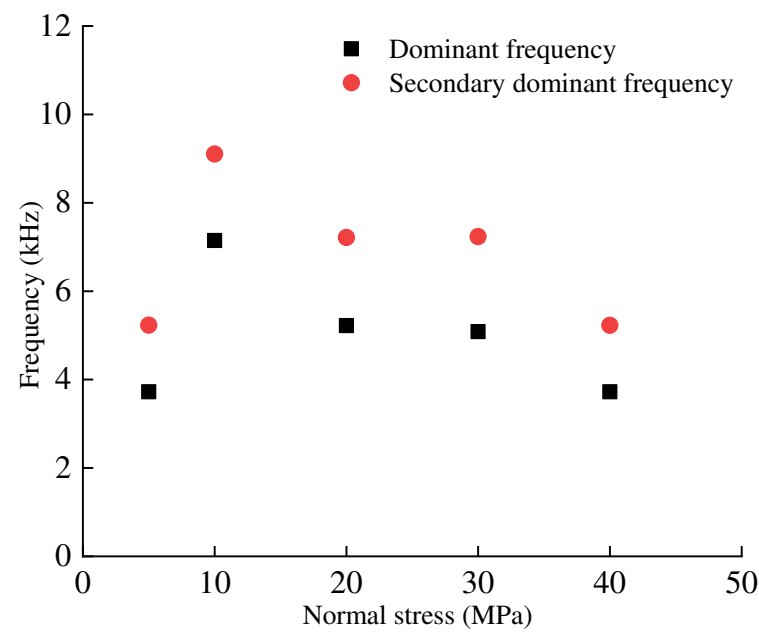

(b) Saturation state

Fig. 9 Variation of the dominant and secondary dominant frequencies of red sandstone with normal stress

Fig. 8 illustrates that the amplitudes of the dominant and secondary dominant frequencies of the shear failure typical $\mathrm{AE}$ waves of the dry red sandstone are significantly greater than those of the saturated red sandstone under the same normal stress. When the normal stress values are 5, 10, 20, 30, and $40 \mathrm{MPa}$, the amplitude ratios of the dominant frequency of dry and saturated red sandstone are 11.60, $2.71,4.51,0.27$, and 1.73 , and those of the secondary dominant frequency of dry and saturated red sandstone are $9.29,4.04,8.85,0.22$, and 1.91 , respectively. The amplitude ratios of the dominant and secondary dominant frequencies of shear failure of dry and saturated red sandstone decrease as a whole with the increase in normal stress. Under normal stress values of $5,10,20,30$, and $40 \mathrm{MPa}$, the ratios of dominant frequency to secondary dominant frequency amplitude in the dry state are $1.70,1.23,1.17,1.36$, and 1.08, respectively, and those of the dominant frequency to secondary dominant frequency amplitude in the saturated state are 1.36, 1.84, 1.52, 1.10 and 1.19, respectively. The results show that normal stress and water saturation have little effect on the ratio of dominant frequency to secondary dominant frequency amplitude of the AE signal of shear failure of red sandstone.

Fig. 8 indicates that the shear failure frequency spectral diagram of dry red sandstone changes from single peak to multiple peaks with the increase in normal stress. The shear failure frequency spectral diagrams of saturated red sandstone show multiple peak characteristics. The amplitudes of dominant and secondary dominant frequencies of red sandstone decrease with the increase in normal stress.

Fig. 9 illustrates that the dominant and secondary dominant frequencies of shear failure of dry and saturated red sandstone decrease with the increase in normal stress. The dominant frequency is less than the secondary dominant frequency. The average values of the ratio of dominant to secondary dominant frequencies of red sandstone in the dry and saturated 
states are 0.56 and 0.73 , respectively. The average dominant frequency ratio of the dry and saturated states is 0.63 , and the average secondary dominant frequency ratio is 0.80 . The overall analysis shows that the dominant and secondary dominant frequencies of red sandstone in the dry state are less than those in the saturated state under the same normal stress. The microscopic analysis shows that the low frequency signal corresponds to the large-scale microcrack, and the high frequency signal corresponds to the small-scale microcrack. Thus, the microcrack scale of red sandstone in the saturated state is less than that in the dry state.

\section{Conclusions}

The following conclusions can be drawn in accordance with the analysis of shear strength, cumulative ring count, cumulative energy, dominant frequency, and secondary dominant frequency of dry and saturated red sandstone under different normal stress:

1) The cumulative ring count and energy curves of AE of dry and saturated red sandstone are divided into linear increase and step jump stages. Many significant steps are observed in the dry state cumulative curves.

2) The cumulative ring count and cumulative energy of red sandstone shear failure increase with the increase in normal stress. Under the same normal stress, the cumulative ring count and cumulative energy of red sandstone in the dry state are greater than those in the saturated state.

3) The shear damage stress of red sandstone is determined according to the cumulative ring count and cumulative energy curves. The shear failure process is divided into crack initiation and crack rapid development zones. The crack initiation zone corresponds to the random generation of microcrack. The crack rapid development zone corresponds to the rapid and unstable development of crack.

4) The shear strength and damage stress of dry and saturated red sandstone linearly increase with the increase in normal stress, and their change rules are basically consistent. The growth rate of red sandstone in the dry state is greater than that in the saturated state.

5) The damage degree is expressed via cumulative ring count, and the relationship between damage degree and shear strain is established.

6) The dominant and secondary dominant frequencies of dry and saturated red sandstone decrease with the increase in normal stress. The dominant frequency is less than the secondary dominant frequency. The overall analysis shows that the dominant and secondary dominant frequencies of red sandstone in dry state are less than those in saturated state.

\section{Acknowledgements}

This work was financially supported by the National Natural Science Foundation of China (U1604142) and the Young Excellent Teacher Project of Henan Polytechnic University (2016XQG-10).

\section{References:}

[1] Shahram Ghasemi, Mashalah Khamehchiyan, Abbas Taheri, Mohammad Reza Nikudel, Ahmad Zalooli. Crack evolution in damage stress thresholds in different minerals of granite rock $[\mathrm{J}]$. Rock Mechanics and Rock Engineering, 2020, 53:1163-1178.

[2] Thomas Bruning, Murat Karakus, Giang D. Nguyen, David Goodchild. Experimental study on the damage evolution of brittle rock under triaxial confinement with full circumferential strain control[J]. Rock Mechanics and Rock Engineering, 2018, 51:3321-3341.

[3] Mahdi Saadat, Abbas Taheri. A cohesive grain based model to simulate shear behaviour of rock joints with asperity damage in polycrystalline $\operatorname{rock}[\mathrm{J}]$. Computers and Geotechnics, 2020, 117, Article 103254.

[4] Zenghui Zhao, Weiming Wang, Lihua Wang, Chunquan Dai. Compression-shear strength criterion of coal-rock combination model considering interface effect[J]. Tunnelling and Underground Space Technology, 2015, 47: 193-199.

[5] Marion Bost, Hussein Mouzannar, Fabrice Rojat, Grégory Coubard, Jean Pierre Rajot. Metric scale study of the bonded concrete-rock interface shear behavior[J]. KSCE Journal of Civil Engineering, 2020, 24(2):390-403.

[6] Z. A. Moradian, G. Ballivy, P. Rivard, C. Gravel, B.Rousseau. Evaluating damage during shear tests of rock joints using acoustic emissions[J]. International Journal of Rock Mechanics and Mining Sciences, 2010, 47(4): 590-598.

[7] Y. Wang, J. Q. Han, C. H. Li. Acoustic emission and CT investigation on fracture evolution of granite containing two flaws subjected to freeze-thaw and cyclic uniaxial increasing-amplitude loading conditions[J]. Construction and Building Materials, 2020, 260, 119769.

[8] Guangcheng Shi, Xiaojie Yang, Huaichang Yu, Chun Zhu. Acoustic emission characteristics of creep fracture evolution in double-fracture fine sandstone under uniaxial compression[J]. Engineering Fracture Mechanics, 2019, 210:13-28.

[9] Patricia Rodríguez, Tarcisio B. Celestino. Application of acoustic emission monitoring and signal analysis to the qualitative and quantitative characterization of the fracturing process in rocks[J]. Engineering Fracture Mechanics, 2019, 210: 54-69.

[10]Eyvind Aker, Daniela Kühn, Václav Vavryčuk, Magnus Soldal, Volker Oye. Experimental investigation of acoustic emissions and their moment tensors in rock during failure $[\mathrm{J}]$. International Journal of Rock Mechanics and Mining Sciences, 2014, 70: 286-295.

[11]Ruibiao Mao, Zijun Feng, Zhenghe Liu, Yangsheng Zhao. Laboratory hydraulic fracturing test on large-scale pre-cracked granite specimens[J]. Journal of Natural Gas Science and Engineering, 2017, 44: 278-286.

[12]Gang Wang, Yongzheng Zhang, Yujing Jiang, Peixun Liu, Yanshuang Guo, Jiankang Liu, Ming Ma, Ke Wang, Shugang Wang. Shear behaviour and acoustic emission characteristics of bolted rock joints with diferent roughnesses[J]. Rock Mechanics and Rock Engineering, 2018, 51: 1885-1906.

[13]A. C. Mpalaskas, T. E. Matikas, D. Van Hemelrijck, G. S. Papakitsos, D. G. Aggelis. Acoustic emission monitoring of 
granite under bending and shear loading $[\mathrm{J}]$. Archives of Civil and Mechanical Engineering, 2016, 16: 313-324.

[14]Yuanchao Zhang, Yujing Jiang, Daisuke Asahina, Changsheng Wang. Experimental and numerical investigation on shear failure behavior of rock-like samples containing multiple non-persistent joints[J]. Rock Mechanics and Rock Engineering, 2020, https://doi.org/10.1007/s00603-020-02186-0.

[15]Shkuratnik, V. L., Kravchenko, O. S. , Filimonov, Y. L. Stresses and temperature affecting acoustic emission and rheological characteristics of rock salt[J]. Journal of Mining Science, 2019, 55: 531-537.

[16] Shujian Li, Dongming Zhang, Xin Bai, Xianmeng Zhang, Yapei Chu, Kunyong Guo. Experimental study on mechanical properties, acoustic emission energies and failure modes of pre-cracked rock materials under uniaxial compression[J]. Pure and Applied Geophysics, 2019, 176: 4519-4532.

[17]Zabihallah Moradian, Herbert H. Einstein, Gerard Ballivy. Detection of cracking levels in brittle rocks by parametric analysis of the acoustic emission signals[J]. Rock Mechanics and Rock Engineering, 2016, 49: 785-800.

[18]Vinoth Srinivasan, Ashutosh Tripathy, Tushar Gupta, T. N.
Singh. An investigation on the infuence of thermal damage on the physical, mechanical and acoustic behavior of indian Gondwana shale[J]. Rock Mechanics and Rock Engineering, 2020, 53: 2865-2885.

[19]Claudia Barile, Caterina Casavola, Giovanni Pappalettera Vimalathithan Paramsamy Kannan. Application of different acoustic emission descriptors in damage assessment of fiber reinforced plastics: A comprehensive review[J]. Engineering Fracture Mechanics, 2020, 235, Article 107083.

[20]Yanbo Zhang, Wenrui Wu, Xulong Yao, Peng Liang, Lin Sun, Xiangxin Liu. Study on spectrum characteristics and clustering of acoustic emission signals from rock fracture[J]. Circuits, Systems, and Signal Processing, 2020, 39:1133-1145.

[21]Xiangxin Liu, Lixin Wu, Yanbo Zhang, Zhengzhao Liang, Xulong Yao, Peng Liang. Frequency properties of acoustic emissions from the dry and saturated $\operatorname{rock}[\mathrm{J}]$. Environmental Earth Sciences, 2019, 78: 67.

[22]Kachanov L M. Time rupture process under creep conditions [J]. Izvestia Akademii Nauk SSSR, Otdelenie Tekhnicheskich Nauk, 1958, 8:26-31 
Figures

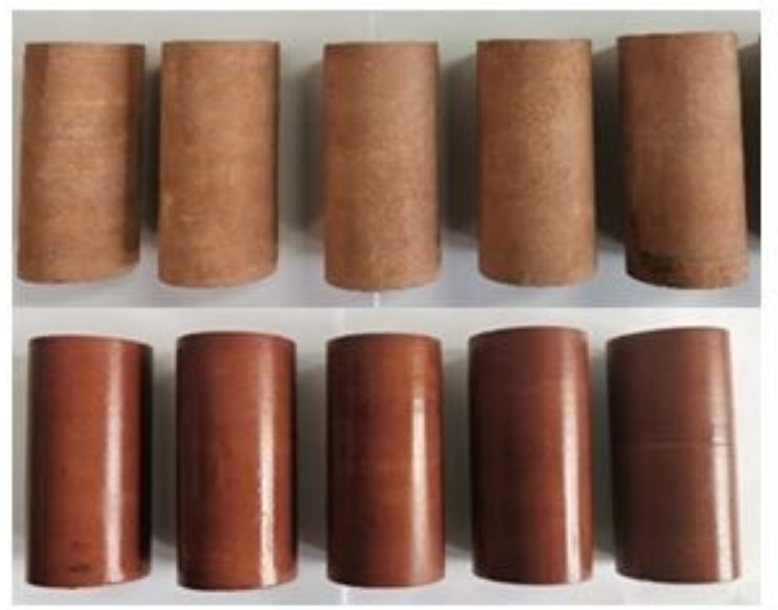

Figure 1

Dry and saturated samples of red sandstone

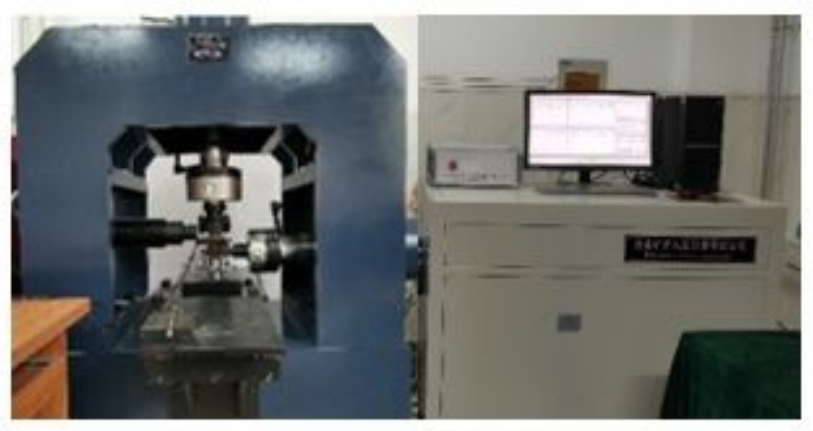

Figure 2

Direct shear test device 


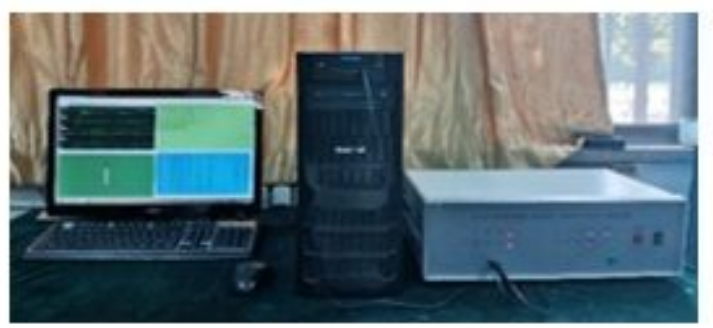

(a) Monitoring system of $\mathrm{AE}$

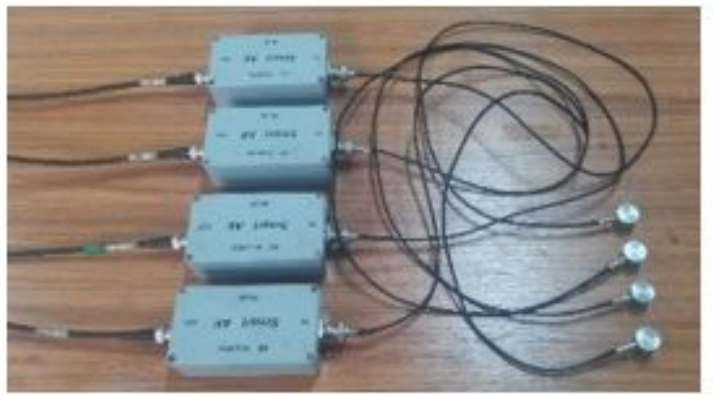

(b) Amplifiers and monitoring probes

Figure 3

AE monitoring system 


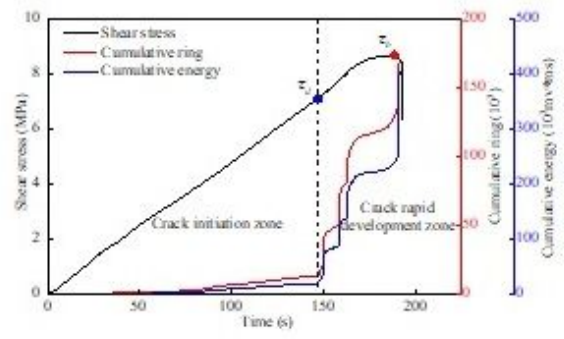

(a, 1 ) Dry state (5 MPa)

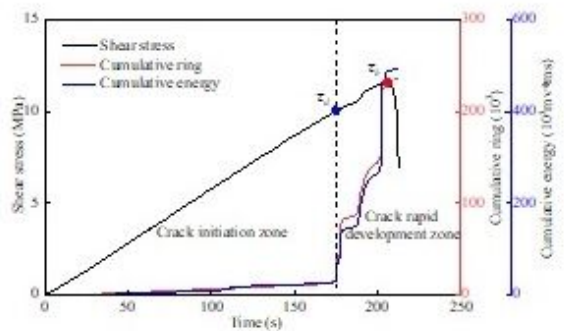

(bu10) Dry state (10 MPa)
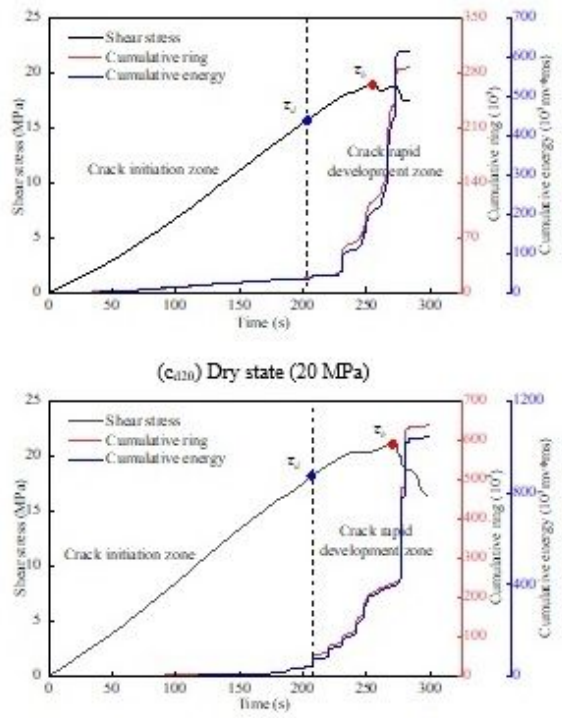

(dw) Dry state (30 MPa)

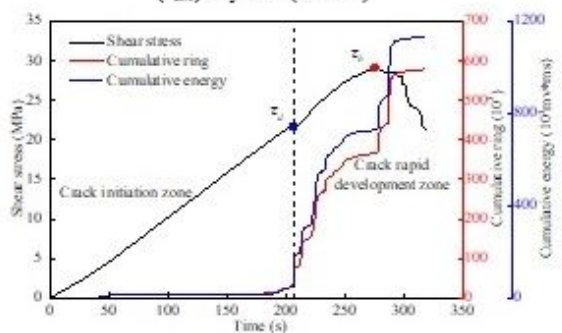

(e:40) Dry state $(40 \mathrm{MPa})$

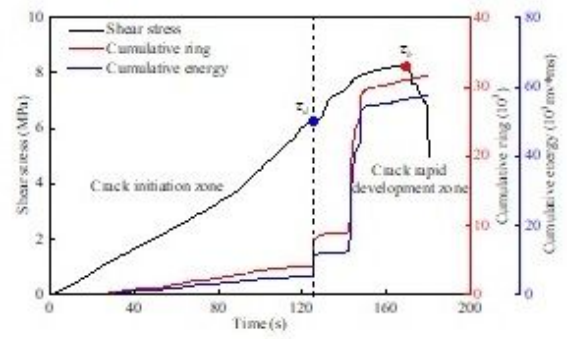

(a,s) Saturation state (5 MPa)

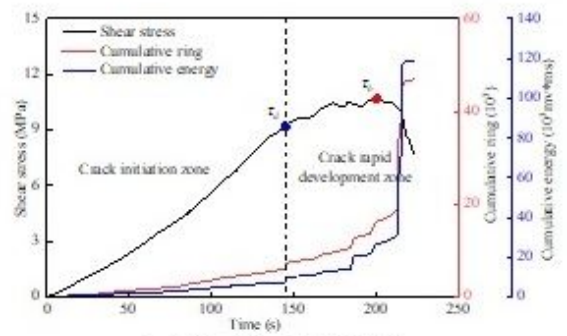

$\left(b_{110}\right)$ Saturation state $(10 \mathrm{MPa})$
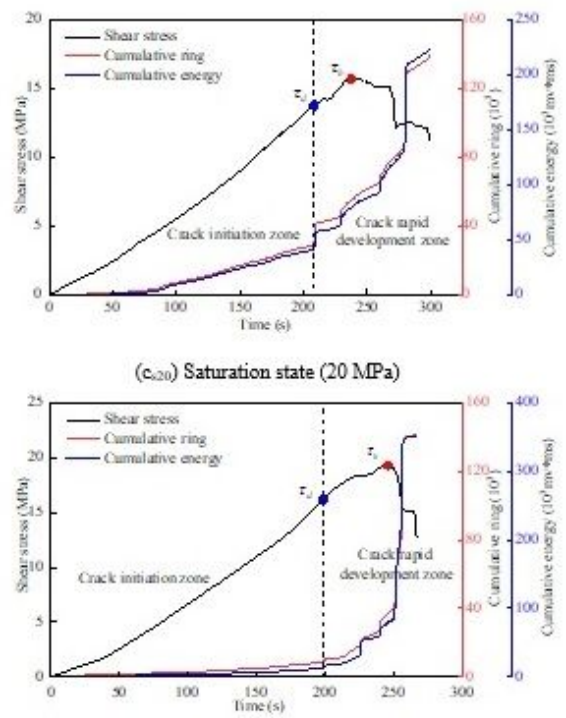

(d.30) Saturation state $(30 \mathrm{MPa})$

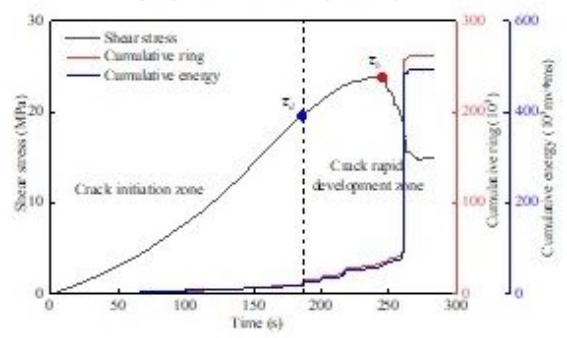

(e.40) Saturation state (40MPa)

\section{Figure 4}

$A E$ cumulative ring count and energy curves of the dry and saturated red sandstone 


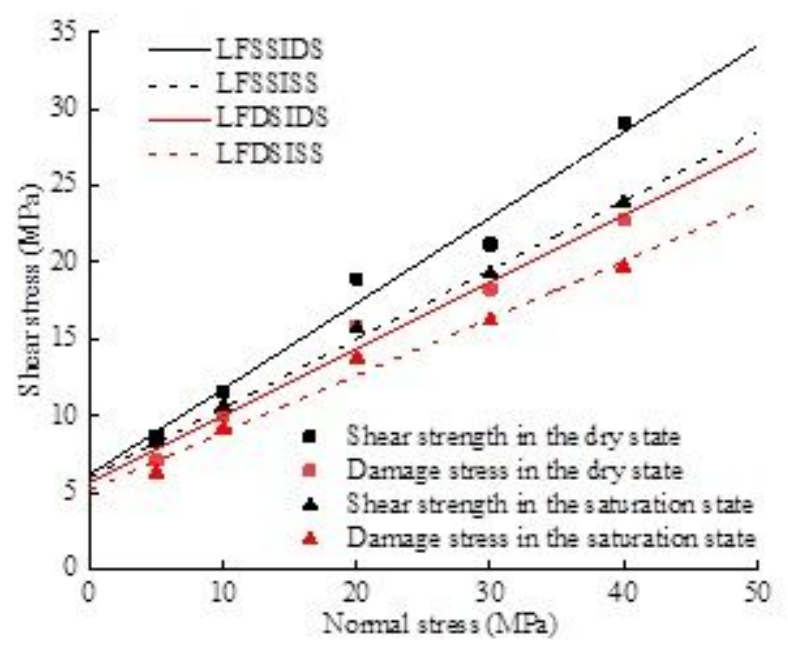

Figure 5

Shear strength and damage stress of red sandstone under different normal stresses

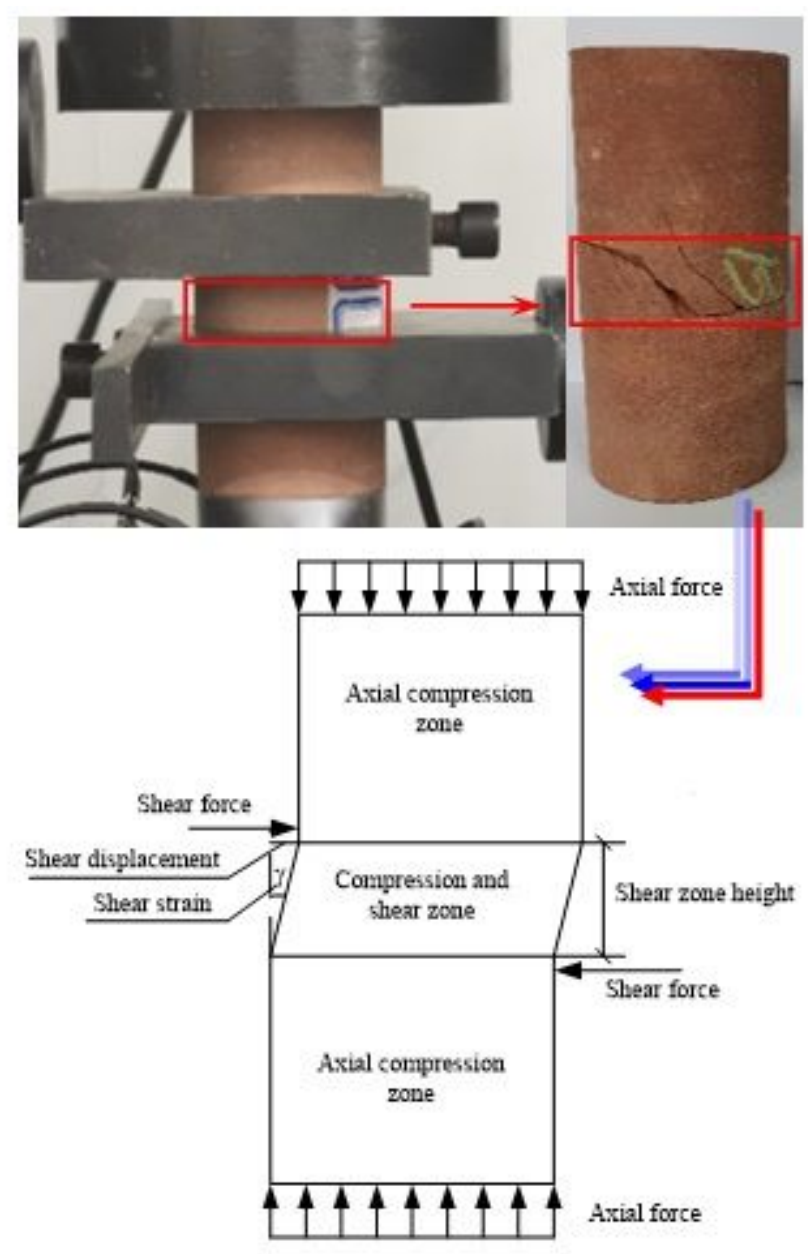

Figure 6

Diagram of the shear strain calculation 


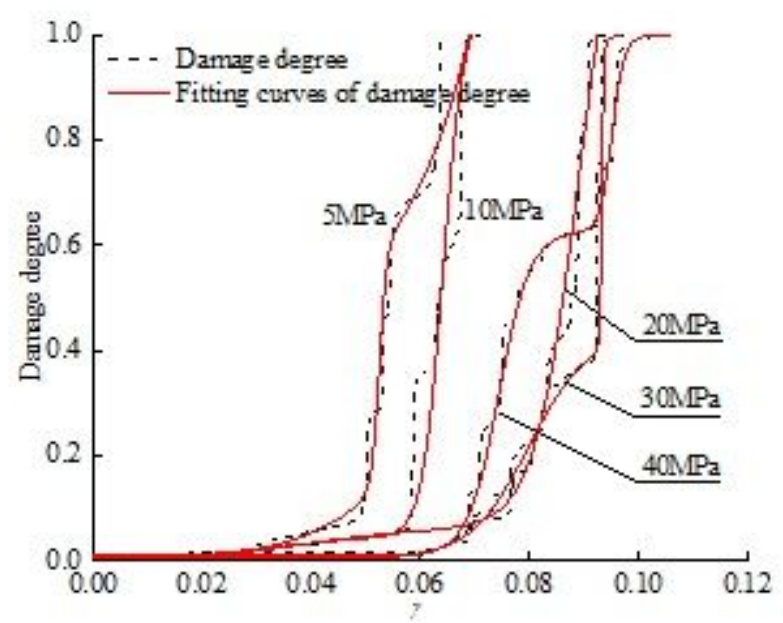

(a) Dry state

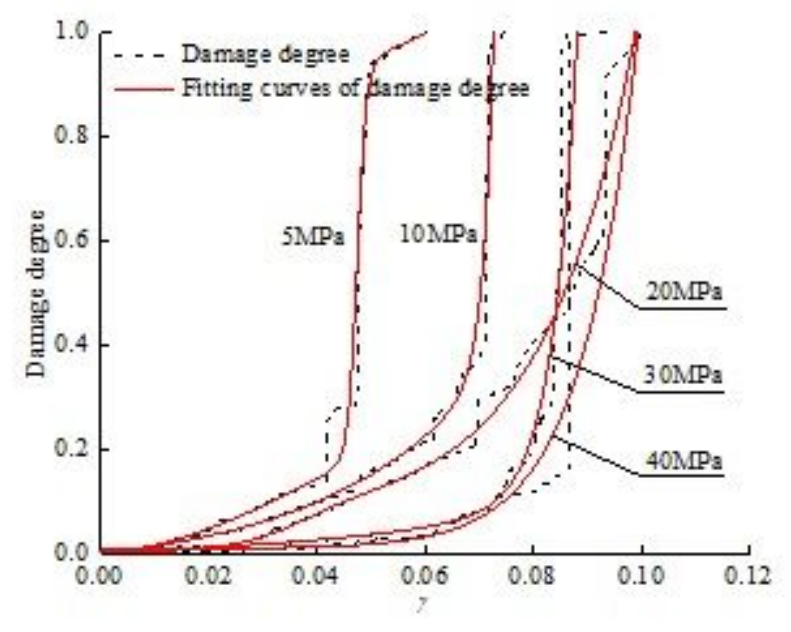

(b) Saturated state

\section{Figure 7}

Variation of the damage degree of red sandstone with shear strain in the dry and saturated states 

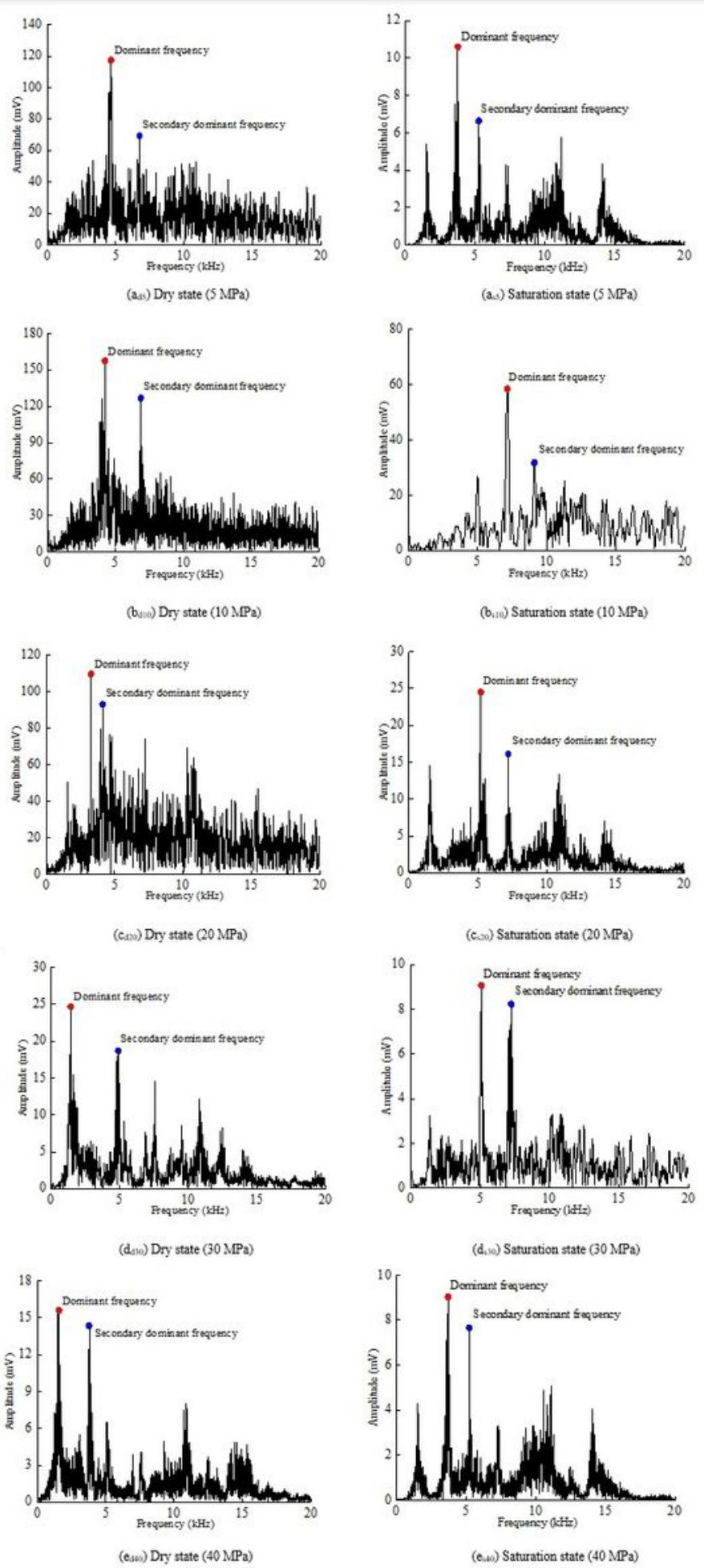

Figure 8

Frequency spectral characteristics of $A E$ of the dry and saturated red sandstone 


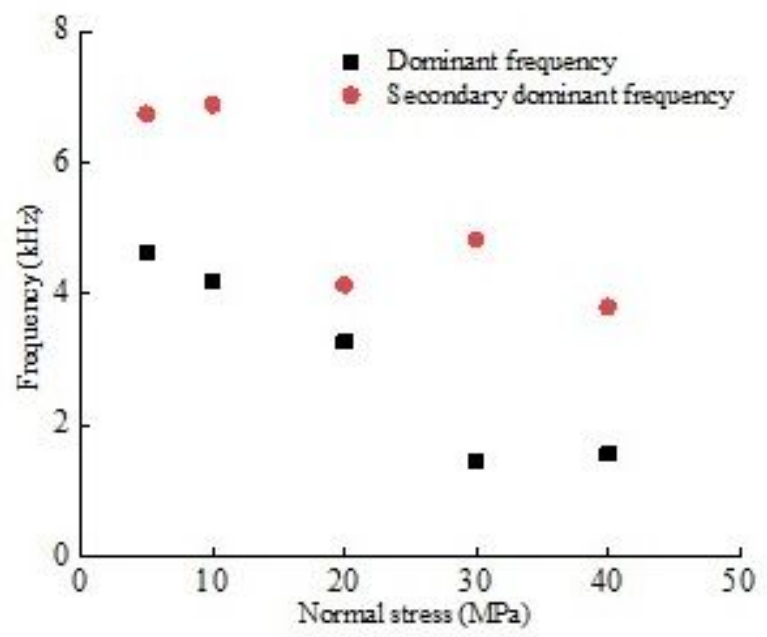

(a) Dry state

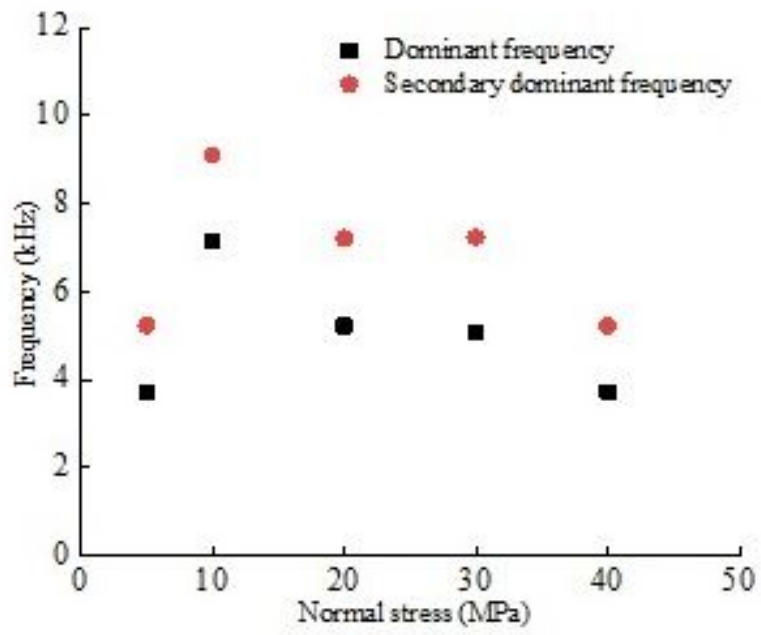

(b) Saturation state

\section{Figure 9}

Variation of the dominant and secondary dominant frequencies of red sandstone with normal stress 